\title{
Interacción de rotavirus con la proteína disulfuro-isomerasa in vitro y en sistemas celulares
}

\author{
Martha N. Calderón', Carlos A. Guerrero², Yohana Domínguez³, Eliana Garzón, \\ Sandra M. Barreto ${ }^{3}$, Orlando Acosta ${ }^{2}$ \\ 1 Departamento de Química, Facultad de Ciencias, Universidad Nacional de Colombia, Bogotá, D.C., Colombia \\ 2 Departamento de Ciencias Fisiológicas, Instituto de Biotecnología, Facultad de Medicina, Universidad Nacional \\ de Colombia, Bogotá, D.C., Colombia \\ 3 Departamento de Bacteriología, Facultad de Ciencias de la Salud, Universidad Colegio Mayor de Cundinamarca, \\ Bogotá, D.C., Colombia
}

Introducción. La entrada del rotavirus a la célula implica un mecanismo de múltiples pasos; las proteínas virales externas interaccionan con cuatro diferentes integrinas y Hsc70. Recientemente reportamos que la infección por rotavirus disminuye cuando se bloquea la proteína disulfuro-isomerasa de la superficie celular, lo que sugiere su interacción con el rotavirus en el proceso de entrada.

Objetivo. Establecer la interacción del rotavirus con la proteína disulfuro-isomerasa en un sistema in vitro utilizando la proteína aislada de hígado bovino y, en un sistema celular, utilizando vellosidades intestinales de ratón y células MA104.

Materiales y métodos. Se aisló la proteína disulfuro-isomerasa a partir de un homogenizado de hígado bovino utilizando anticuerpos anti-proteína disulfuro-isomerasa acoplados a agarosa mediante enlace hidrazona. La proteína disulfuro-isomerasa purificada se examinó por SDS-PAGE y Western blot y se utilizó para estudiar su interacción in vitro con rotavirus. Esta interacción se comparó con aquella observada en células MA104 y en las vellosidades intestinales de ratón.

Resultados. La proteína disulfuro-isomerasa purificada mostró homogeneidad electroforética y fue capaz de unirse a rotavirus en un sistema in vitro. La interacción proteína-rotavirus fue detectada por ELISA de captura usando la proteína disulfuro-isomerasa bovina purificada y rotavirus de las cepas RRV y silvestre ECwt. La interacción de partículas de rotavirus purificadas con la proteína disulfuroisomerasa celular se evidenció con ELISA, usando lisado celular después de la inoculación viral.

Conclusión. La interacción rotavirus-proteína disulfuro-isomerasa fue demostrada in vitro, en células MA104 y en vellosidades intestinales de ratón lactante.

Palabras clave: rotavirus, proteína disulfuro-isomerasa, receptores virales, intestino delgado, línea celular, cromatografía de afinidad.

\section{Interaction of rotavirus with protein disulfide isomerase in vitro and cell system}

Introduction. Rotavirus entry process involves a multi-step mechanism, the first of which is when the outermost viral proteins interact with four different integrins and Hsc70. Recently, rotavirus infection reportedly has been decreased after blocking cell surface protein disulfide isomerase (PDI). This suggested that this protein interacts with rotavirus during the entry process.

Objectives. The aim was to establish the rotavirus-PDI interaction in an in vitro system using PDI isolated from bovine liver, and in a cell system consisting of MA104 cells and mouse small intestinal villi.

Materials and methods. Protein disulfide isomerase was isolated from a bovine liver homogenate using anti-PDI antibodies coupled to agarose through hydrazone bonds. Purity of purified protein was assessed by SDS-PAGE and Western blot. The purified PDI was used to study its in vitro interaction with the rotavirus particles. This interaction was compared with that taking place in MA104 cells and small intestinal villi isolated from sucking mice ICR.

Results. The purified PDI showed an electrophoretic homogeneity and was able to bind rotavirus particles in vitro. Rotavirus-PDI interaction was detected by capture ELISA using purified protein and rotavirus strains RRV and wild-type ECwt. Interaction between rotavirus particles and cellular PDI was detected by ELISA using cell lysates after virus inoculation.

Conclusions. Rotavirus-PDI interaction was demonstrated in vitro as well as in MA104 cells and intestinal villi from suckling mice.

Key words: Rotavirus; protein disulfide isomerase; virus receptors; small intestine; cell line; affinity chromatography. 
Los rotavirus constituyen la primera causa de gastroenteritis aguda grave en niños menores de cinco años y animales jóvenes. La infección por rotavirus produce deshidratación, y es la causa más significativa de muerte en los infantes de los países en desarrollo. La mortalidad a nivel mundial fluctúa entre 454.000 y 705.000 al año (1-4).

Los rotavirus pertenecen a la familia Reoviridae y sus partículas carentes de cubierta lipídica contienen un genoma de ARNds distribuido en 11 segmentos (5-7). Las proteínas estructurales (VP1VP4, VP6 y VP7) de la partícula viral se distribuyen en tres capas concéntricas. Las partículas con las tres capas proteicas son infecciosas, mientras que aquéllas que poseen solo dos capas proteicas están exentas de capacidad infecciosa pero poseen actividad de transcripción (7).

Se considera que los rotavirus utilizan como receptor funcional un complejo de varias macromoléculas que incluyen, entre otras moléculas, las integrinas av $\beta 3$, a2 $\beta 1$, ax $\beta 2$ y la proteína de choque térmico Hsc70, cuya presencia se ha evidenciado especialmente en la superficie de células MA104 (8-23). Recientemente, en un estudio realizado en nuestro laboratorio (Calderón MN, Acosta O, Guerrero CA, Guzmán F. Protein disulfide isomerase activity is involved in rotavirus entry to MA104 cells. Proceedings of the XIV International Congress of Virology, Istanbul. 2008. p. 163-4), se encontró que bloqueadores de la actividad de la proteína disulfuro-isomerasa de la superficie celular y anticuerpos anti-proteína disulfuro-isomerasa inhiben la infección por rotavirus en células MA104. Estos hallazgos sugieren una mayor complejidad en el mecanismo de entrada del rotavirus a la célula y la existencia de posibles vías alternativas para la entrada de las diferentes cepas de rotavirus a las células huésped $(14,15,21,24)$.

La familia disulfuro-isomerasa comprende varias proteínas que participan en la generación de grupos tiol y la formación e isomerización de puentes de disulfuro en proteínas recientemente sintetizadas en la luz del retículo endoplásmico (25-28). Actúan también como chaperonas y, por consiguiente,

\footnotetext{
Correspondencia:

Carlos A. Guerrero, Laboratorio de Biología Molecular, Facultad de Medicina, Universidad Nacional de Colombia, Carrera 45 № 26-85, edificio 471, Bogotá, D.C., Colombia.

Teléfono: (571) 3165000 , extensión 15053; fax: (571) 3165000 , extensión 15047

caguerrerof@unal.edu.co

Recibido: 23/02/10; aceptado:28/09/10
}

son parte de un sistema de control de calidad del plegamiento correcto de las proteína (26). Estas proteínas se caracterizan por la presencia de uno o más dominios de 95 a 110 aminoácidos, aproximadamente, los cuales presentan similitud con las tioredoxinas citoplásmicas $(29,30)$. Se han encontrado miembros de familia de la proteína disulfuro-isomerasa en el espacio extracelular, el citosol, el núcleo y en la superficie celular (31-39). Los miembros de la familia de la proteína disulfuroisomerasa por fuera del retículo endoplásmico se han encontrado en muy baja concentración y en periodos cortos, del orden de pocos minutos; la dicha proteína se desprende fácilmente de la membrana celular y es remplazada por nuevas moléculas provenientes del interior de la célula, 0 por difusión desde otras células (32-34).

Se ha sugerido que luego de la secreción, la proteína disulfuro-isomerasa se une a la superficie celular por interacciones electrostáticas, por interacción con otras proteínas localizadas en membrana o por ambas $(33,34)$. La función de la proteína disulfuro-isomerasa asociada a la membrana plasmática se ha relacionado con la actividad reductora de la superficie celular y con procesos que incluyen interacción con integrinas, adhesión celular, maduración de las plaquetas, transporte de óxido nítrico, modulación de la actividad de la trombospondina e interacción con el ectodominio del receptor de la tirotropina humana (26,31-39).

La capacidad infecciosa de virus tales como Sindbis (40), VIH (32,41-45), Newcastle (46-48) y de la hepatitis delta (49), se encuentra asociada a la reducción de puentes disulfuro de algunas de sus proteínas estructurales, reducción que es llevada a cabo al menos por la proteína disulfuroisomerasa $(32,41,45,48)$.

En el presente trabajo se diseñó un método de purificación de proteína disulfuro-isomerasa de hígado de bovino, con el fin de realizar estudios de interacción entre ella y la partícula rotaviral in vitro. Se estableció una interacción entre los rotavirus RRV y ECwt con la proteína purificada y aquella de células MA104 y de vellosidades intestinales de ratón lactante.

\section{Materiales y métodos}

\section{Animales, células y virus}

Se obtuvieron ratones lactantes ICR (10 a 12 días de edad) del bioterio del Instituto Nacional de Salud de Colombia. Los ratones se mantuvieron de acuerdo con las normas de bioética institucionales 
(Comité de Ética, Facultad de Medicina, Universidad Nacional de Colombia).

La línea celular MA104, derivada del epitelio de riñón de mono rhesus, fue donada por C. F. Arias (Instituto de Biotecnología, Universidad Autónoma de México). Estas células se cultivaron en medio Advanced-DMEM (Gibco) con suplemento de suero fetal bovino (SFB, Gibco) al $2 \%$, y en incubadora con $5 \%$ de $\mathrm{CO}_{2}$ a $37^{\circ} \mathrm{C}$. Se empleó el rotavirus de la cepa ECwt (EDIM Cambridge WildType; EDIM: Epidemic Diarrhea of Infant Mice), donado por M. Franco (Instituto de Genética de la Pontificia Universidad Javeriana, Bogotá, Colombia).

Se utilizó la cepa de rotavirus RRV (simiana, mono rhesus) donada por C. F. Arias (Instituto de Biotecnología, Universidad Autónoma de México). Para infectar las células, en todos los casos, el virus fue activado con tripsina $(1 \mu \mathrm{g} / \mathrm{ml})$ durante 30 minutos a $37^{\circ} \mathrm{C}$.

\section{Extracción y aislamiento de vellosidades intestinales de ratón lactante}

Para extraer las vellosidades del intestino delgado, se siguió la técnica estandarizada en nuestro laboratorio (50). Los ratones, fueron sacrificados por dislocación cerebro-cervical; se extrajo el intestino y se lavó con MEM. El intestino cortado en fragmentos fue incubado en MEM que contenía EDTA 1,5 mM, por 15 minutos a $37{ }^{\circ} \mathrm{C}$ en un agitador orbital a $200 \mathrm{rpm}$. El tejido fue filtrado a través de una malla metálica de poro de $1 \mathrm{~mm}^{2}$. La fracción sólida retenida en la malla se sometió a una segunda extracción. Se mezclaron las dos extracciones celulares correspondientes a las vellosidades intestinales y se recolectaron por centrifugación a $600 \mathrm{~g}$, descartándose el sobrenadante. Las vellosidades se suspendieron en MEM, se midió su viabilidad celular mediante azul de tripano y se utilizaron inmediatamente en los ensayos de interacción con proteína disulfuro-isomerasa.

\section{Propagación de las cepas de rotavirus}

Se infectaron células confluentes de la línea MA104 con un lisado celular de RRV activado con tripsina. Las células se incubaron a $37^{\circ} \mathrm{C}$ hasta la lisis celular; se recuperó el lisado y se almacenó a $-20^{\circ} \mathrm{C}$ hasta su uso. El lisado celular fue congelado y descongelado dos veces y titulado por su actividad infecciosa en términos de unidades formadoras de foco (21).

Para multiplicar el rotavirus ECwt (no es posible propagar esta cepa de rotavirus en las líneas celulares), a 20 ratones lactantes ICR se les suministró $80 \mu \mathrm{l}$ de una preparación viral 10X, cuya dilución 1/10 había sido capaz de infectar el $50 \%$ de las células de vellosidades intestinales aisladas (50). Después de tres días de inoculación, los ratones se sacrificaron para obtener el intestino delgado y a partir de éste purificar el virus utilizando un protocolo que incluye tratamiento con freón (21).

\section{Purificación de rotavirus}

El lisado viral cosechado de células MA104 infectadas con rotavirus RRV o de intestino delgado de ratones infectados con ECwt, se utilizó para purificar el virus siguiendo un método reportado anteriormente (21). En forma resumida, el lisado viral se extrajo con 1,1,2-triclorotrifluoretano (Freón, Sigma) (1:1/3 vol:vol), la emulsión se centrifugó a $13.000 \mathrm{~g}$ por 10 minutos a $4{ }^{\circ} \mathrm{C}$, el sobrenadante fue recolectado y a la fracción orgánica se le adicionó TNC (Tris-HCl $10 \mathrm{mM}, \mathrm{NaCl} 150 \mathrm{mM}, \mathrm{MgCl}_{2} 1 \mathrm{mM}$ $\mathrm{M}, \mathrm{CaCl}_{2} 10 \mathrm{mM}, \mathrm{pH}$ 7,4) en una proporción 1:1 (vol:vol) para someterla a una nueva extracción. Las fracciones acuosas fueron recuperadas y reunidas para ser centrifugadas a $101.500 \mathrm{~g}$ por 1 hora y 30 minutos a $4{ }^{\circ} \mathrm{C}$. El virus fue suspendido en TNC y centrifugado a $217.100 \mathrm{~g}$ por 1 hora a $4{ }^{\circ} \mathrm{C}$ en un gradiente discontinuo de $\mathrm{CsCl}(0,5 \mathrm{ml}$ con densidad 1,4157; $1 \mathrm{ml}$ con densidad 1,3039; $0,5 \mathrm{ml}$ con densidad 1,2070 y $0,5 \mathrm{ml}$ de sacarosa al $30 \%$ ). Las bandas que contenían las tres capas proteicas y las dos capas proteicas se recolectaron separadamente, se diluyeron con solución tampón TNC y se recuperaron por centrifugación $(120.000 \mathrm{~g}$ por 1 hora y 30 minutos).

\section{Producción de anticuerpos policlonales contra la proteína disulfuro-isomerasa}

Se inoculó un conejo Nueva Zelanda con proteína disulfuro-isomerasa comercial (Sigma). Se utilizaron $83 \mu \mathrm{g}$ por dosis, en tres aplicaciones en un esquema de 15,30 y 45 días. La primera inoculación se hizo con adyuvante completo de Freund y las dos últimas, con adyuvante incompleto (51). El conejo se sangró por punción cardiaca para obtener el suero hiperinmune contra la proteína disulfuroisomerasa. Tanto el suero preinmune como el hiperinmune fueron analizados mediante Western blot e inmunocitoquímica para la detección de proteína disulfuro-isomerasa y de las proteínas del rotavirus, buscando descartar cualquier posible reacción cruzada o infección previa del conejo con rotavirus. 
Para la prueba inmunocitoquímica, se aislaron los enterocitos de ratón infectados o no infectados con rotavirus RRV; se fijaron a una laminilla y se analizaron con los sueros preinmune e hiperinmune de conejo y, además, con anticuerpos anti-rotavirus generados en conejo en nuestro laboratorio (51), en una dilución 1:1.000. Como anticuerpo secundario, se utilizó anti-conejo acoplado a peroxidasa (HRP) (1:3.000) (Santa Cruz Biotechnology) y el sistema amino-etil-carbazol-peróxido de hidrogeno (AEC$\mathrm{H}_{2} \mathrm{O}_{2}$ ) para la detección.

\section{Preparación del extracto proteico de hígado de bovino}

Se liberó de tejido graso y conectivo un hígado de bovino y se preservó a $4{ }^{\circ} \mathrm{C}$ en PBS $(\mathrm{NaCl} 137 \mathrm{mM}$, $\mathrm{KCl} 2,68 \mathrm{mM}, \mathrm{Na}_{2} \mathrm{HPO}_{4} 6,45 \mathrm{mM}, \mathrm{KH}_{2} \mathrm{PO}_{4} 1,47$ $\mathrm{mM}, \mathrm{pH} 7,2)$. El hígado se cortó en fracciones, fue lavado y diluido con PBS frío que contenía EDTA 5 $\mathrm{mM}$. Se realizó un proceso de homogenización de tres pulsos de 30 segundos en un homogenizador (Omni International Tissue Homogenizator Master 125). El extracto fue centrifugado a $17.000 \mathrm{~g}$ por 30 minutos; el sobrenadante se filtró para la remoción de la capa lipídica. Se guardó en alícuotas de $1 \mathrm{ml}$ a $-70{ }^{\circ} \mathrm{C}$ hasta su uso.

La concentración de proteína se determinó por el método de Bradford. El extracto se analizó por electroforesis en gel de poliacrilamida (10\%) con SDS (SDS-PAGE) y Western blot, teniendo como referencia la proteína disulfuro-isomerasa (Sigma). Se utilizó como anticuerpo primario el anti-proteína disulfuro-isomerasa generado en conejo (1:1.000), uno comercial (Santa Cruz, Biotechnology) y otro producido para este trabajo en nuestro laboratorio. Como anticuerpo secundario, se utilizó el anticonejo acoplado a fosfatasa alcalina (1:3.000) (Santa Cruz, Biotechnology); las bandas de proteína reactivas se revelaron con el sustrato BCIP/NTB (Sigma) en solución tampón Tris-HCl 20 $\mathrm{mM}, \mathrm{NaCl} 150 \mathrm{mM}, \mathrm{MgCl}_{2} 5 \mathrm{mM}, \mathrm{pH}$ 9,5.

\section{Purificación de la proteína disulfuro-isomerasa de hígado de bovino}

Para la purificación de proteína disulfuro-isomerasa de hígado de bovino por cromatografía de afinidad, se preparó la fase estacionaria mediante el acople de los anticuerpos anti-proteína disulfuro-isomerasa al soporte Affi gel hidrazide (BioRad), siguiendo las instrucciones del fabricante.

Para la preparación del soporte cromatográfico, el suero hiperinmune fue tratado con ácido caprílico, y la fracción enriquecida en globulinas fue precipitada con sulfato de amonio saturado en PBS. La solución de globulinas enriquecida en anticuerpos anti-proteína disulfuro-isomerasa se dializó a $4{ }^{\circ} \mathrm{C}$ contra PBS en membrana de celulosa (Millipore) de exclusión 12 kDa. La concentración de la fracción que contenía los anticuerpos antiproteína disulfuro isomerasa se leyó a $280 \mathrm{~nm}$ en un espectrofotómetro de luz ultravioleta, usando albúmina sérica bovina (BSA) (Pierce) como estándar de concentración.

Para la oxidación de las unidades de carbohidrato de los anticuerpos, se hizo un intercambio de la solución tampón PBS de la solución de anticuerpos por solución tampón de acople (acetato de sodio 20 $\mathrm{mM}, \mathrm{pH} 5,5)$ mediante cromatografía de exclusión por tamaño, utilizando Sephadex G-25. La solución de anticuerpos anti-proteína disulfuro-isomerasa se hizo reaccionar con m-peryodato de sodio $29,2 \mathrm{mM}$ en la oscuridad por 1 hora a temperatura ambiente. Se adicionó glicerol $20 \mathrm{mM}$, se mezcló por 10 minutos con el fin de inactivar el peryodato remanente y se dializó contra solución tampón de acople.

La solución de anticuerpos oxidados se adicionó en relación de $4 \mathrm{mg} / \mathrm{ml}$ de gel al soporte Affi gel hidrazide, previo equilibrio de esta solución tampón de acople; se permitió la reacción por 12 horas a temperatura ambiente. Luego de ese tiempo, la resina se lavó con PBS- $\mathrm{NaCl} 0,5 \mathrm{M}$, controlando la salida de anticuerpos no acoplados. La columna cromatográfica de afinidad se equilibró con PBS.

El extracto de hígado de bovino se centrifugó a $17.000 \mathrm{~g}$ por 10 minutos a $4{ }^{\circ} \mathrm{C}$ y se aplicó a la columna de afinidad en una concentración de 50 $\mathrm{mg} / \mathrm{ml}$, utilizando como fase móvil PBS a un flujo de $1 \mathrm{ml} /$ minuto. Se recogieron fracciones de $3 \mathrm{ml}$, se controló a $280 \mathrm{~nm}$ el lavado de la columna hasta no detectar elución de proteínas. La proteína disulfuroisomerasa se eluyó con glicina- $\mathrm{HCl} 0,2 \mathrm{M}, \mathrm{pH} 2,5$, y los eluidos fueron recibidos en $7 \mu$ de Tris- $\mathrm{HCl} 1$ $\mathrm{M}, \mathrm{pH} 11$, con el fin de neutralizar rápidamente la preparación de proteínas. La columna se lavó con PBS. Los eluidos se analizaron por SDS-PAGE y Western blot. Las fracciones que contenían proteína disulfuro-isomerasa se reunieron y se precipitaron con sulfato de amonio hasta el $85 \%$ de saturación; se centrifugó para recuperar los precipitados, los cuales se diluyeron y dializaron contra PBS.

\section{Interacción rotavirus-proteína disulfuro- isomerasa}

Se incubaron $500 \mathrm{ng}$ de las tres capas proteicas de rotavirus RRV o ECwt con diferentes 
concentraciones de proteína disulfuro-isomerasa (se utilizó tanto la proteína comercial como la purificada para este trabajo), en un volumen final de $50 \mu \mathrm{l}$ por 1 hora a temperatura ambiente. La placa de ELISA se recubrió con $50 \mu \mathrm{l}$ de anticuerpo de captura anti-rotavirus durante toda la noche a $4^{\circ} \mathrm{C}$.

Para el análisis de la interacción de proteína disulfuro-isomerasa con la cepa RRV, se utilizó como anticuerpo de captura anti-rotavirus generado en cabra (1:1.000); para el análisis de la interacción de proteína disulfuro-isomerasa con la cepa ECwt, se utilizó un anticuerpo anti-rotavirus ECwt generado en cobayo (1:250). Los anticuerpos anti-rotavirus generados en cabra o cobayo se produjeron de acuerdo con un procedimiento previamente descrito (51).

Luego de bloquear la placa con leche descremada al 5\% en PBS-Tween 20 (0,05\%), se adicionó el complejo rotavirus-proteína disulfuro-isomerasa en un volumen de $50 \mu \mathrm{l}$ y se incubó a $37^{\circ} \mathrm{C}$ durante 2 horas. La placa se lavó con PBS-Tween 20 y se agregó el anticuerpo primario policlonal antiproteína disulfuro-isomerasa $(1: 1.000)$ de conejo y se incubó durante 2 horas a $37^{\circ} \mathrm{C}$. Después de lavada la placa, se adicionó el anticuerpo secundario anti-conejo conjugado con HRP (1:3.000) durante 1 hora; luego de los lavados, la placa se reveló con OPD (dihidrocloruro de O-fenilenediamina, Pierce) a $1 \mathrm{mg} / \mathrm{ml}$ en solución tampón de citratofosfato de sodio, a pH 5,5. La absorbancia se leyó a $492 \mathrm{~nm}$. Al valor promedio de absorbancia de cada tratamiento se le restó el valor promedio de los controles (pozos que contenían como antígeno rotavirus, BSA o proteína disulfuro-isomerasa) y se graficó como delta de absorbancia.

La interacción entre rotavirus con proteína disulfuroisomerasa proveniente de las células MA104 o de las vellosidades intestinales de ratón, también se analizó con la técnica de ELISA de captura. El rotavirus activado con tripsina se incubó a $0{ }^{\circ} \mathrm{C}$ durante 45 minutos con las células MA104 o con las vellosidades aisladas de intestino de ratón, y luego se incubó a 0, 30 y 60 minutos a $37^{\circ} \mathrm{C}$. Las células se lavaron y lisaron con solución tampón de lisis (Tris- $\mathrm{HCl} 50 \mathrm{mM}, \mathrm{NaCl} 150 \mathrm{mM}$, ditiotreitol 2 $\mathrm{mM}$, Nonident P-40 al $1 \%$, deoxicolato de sodio al $0,5 \%$, Triton $\mathrm{X}-100$ al $1 \%, \mathrm{pH} 8,0)$. El lisado celular se centrifugó y se aplicaron $50 \mu \mathrm{l}$ del sobrenadante a la placa de ELISA previamente recubierta con anticuerpos anti-rotavirus, como se mencionó anteriormente. Al valor promedio de absorbancia de cada tratamiento se le restó el valor promedio del control (lisado celular no infectado) y se graficó como delta de absorbancia.

\section{Resultados}

\section{Caracterización de anticuerpos policlonales anti-proteína disulfuro-isomerasa}

La fracción de globulinas del suero enriquecida con anticuerpos anti-proteína disulfuro-isomerasa se tituló para su uso en la técnica de Western blot, utilizando proteína comercial como antígeno. Se observó que hasta la dilución 1:3.000 del anticuerpo anti-proteína disulfuro-isomerasa, se detectó el antígeno como una banda a nivel de $57 \mathrm{kDa}$ (figura 1A). Se detectaron bandas reactivas de menor peso molecular que podrían corresponder a productos de la degradación proteolítica de proteína disulfuro-isomerasa. Para la caracterización del anticuerpo anti-proteína disulfuro-isomerasa utilizado en la técnica de ELISA, se incubó la placa con diferentes concentraciones de la proteína comercial $(5,10,20$ y $40 \mu \mathrm{g} / \mathrm{ml})$ y luego con diferentes diluciones del anticuerpo antiproteína disulfuro isomerasa $(1: 1.000,1: 2.000$ y 1:4.000) (figura 1B). Los resultados indican que, para la técnica de ELISA, la concentración mínima de proteína y la máxima dilución del anticuerpo anti-proteína disulfuro-isomerasa que generan una señal de reconocimiento confiable, es de $20 \mu \mathrm{g} / \mathrm{ml}$ de dicha proteína (1 $\mathrm{\mu g}$ de proteína por pozo) y hasta 1:4.000 de dilución del anticuerpo.

Los sueros preinmune e hiperinmune del conejo inmunizado con proteína disulfuro-isomerasa se analizaron en la detección de las proteínas rotavirales. El suero preinmune y el hiperinmune no presentaron reactividad hacia las tres capas proteicas purificadas, como lo indica el resultado de Western blot de las tres capas proteicas de RRV, usando los anticuerpos anti-proteína disulfuroisomerasa en dilución 1:200 de anticuerpo primario (figura 1C); dicho anticuerpo no reconoció al rotavirus en células infectadas y analizadas por inmunocitoquímica (figura 1D).

\section{Extracción y purificación de proteína disulfuro- isomerasa de hígado de bovino}

Se detectó proteína disulfuro-isomerasa en el extracto de hígado de bovino cuando se analizó con el anticuerpo anti-proteína disulfuro-isomerasa comercial o con el anticuerpo generado en conejo (figuras $2 \mathrm{~A}$ y $2 \mathrm{~B}$ ). La cromatografía de afinidad utilizando anticuerpos anti-proteína disulfuroisomerasa acoplados al Affi gel hidrazide mediante 
A

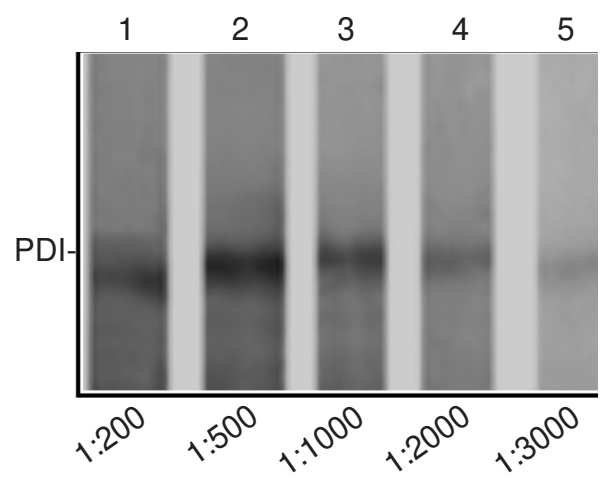

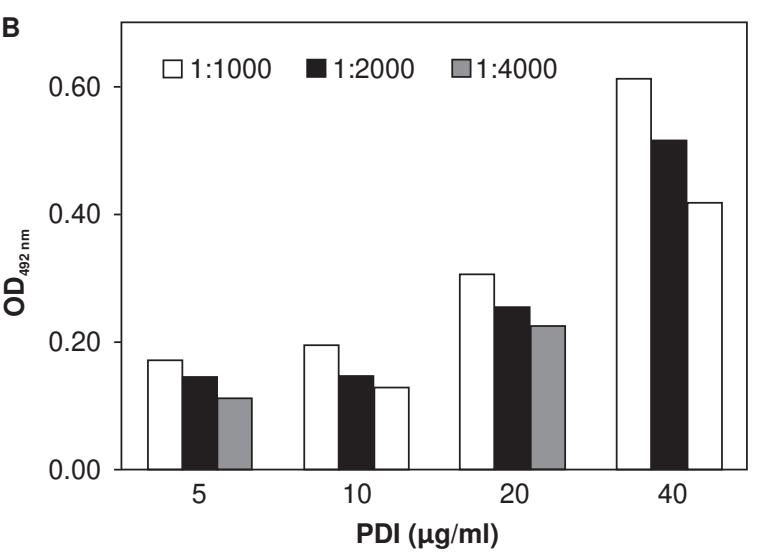

D
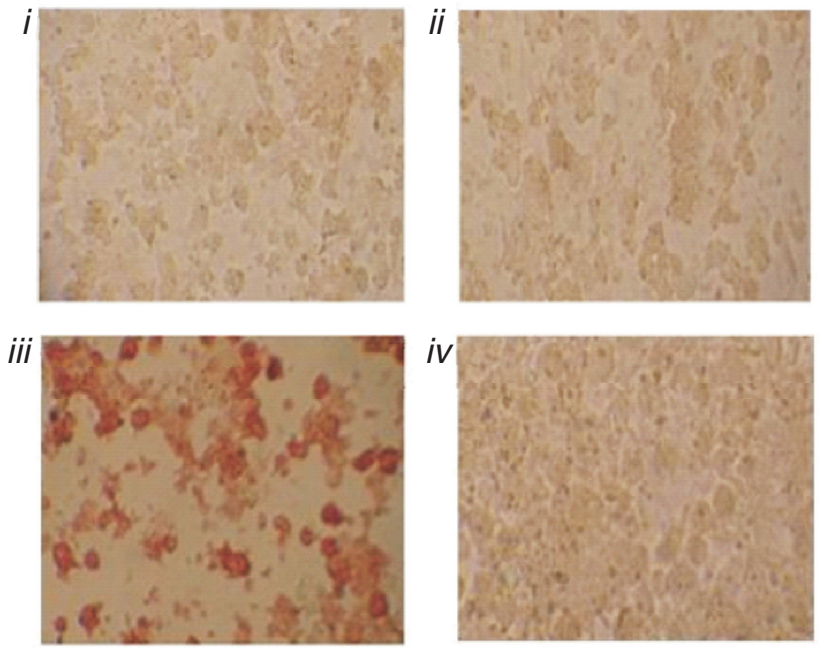

Figura 1. Caracterización parcial del anticuerpo policlonal anti-proteína disulfuro-isomerasa generado en conejo. (A) Detección de proteína disulfuro-isomerasa ( $1 \mu \mathrm{g}$ por tira) por Western blot con las diluciones que se indican de suero hiperinmune de conejo que contiene anticuerpos anti-proteína disulfuro-isomerasa, la detección se realizó con anticuerpos anti-conejo-HRP. (B) Proteína disulfuro-isomerasa en las concentraciones indicadas fue detectada mediante ELISA, utilizando como anticuerpo primario diluciones de suero de conejo y como anticuerpo secundario anti-conejo-HRP. El valor de absorbancia corresponde a la diferencia entre las absorbancias de los tratamientos menos aquellas que corresponden a la línea de base del experimento, se muestran los promedios y las desviaciones estándar de uno de dos experimentos independientes realizados por duplicado. (C) Detección de las proteínas estructurales del rotavirus, las tres capas proteicas $(1 \mu \mathrm{g}$ por tira) por Western blot con el suero de conejo que contiene anticuerpos anti-proteína disulfuro-isomerasa (línea 1) y con anticuerpos anti-rotavirus (línea 2). (D) Enterocitos infectados con rotavirus RRV ( $i$, ii, iii) o no infectados (iv) analizados mediante inmunocitoquímica para la detección de proteína disulfuro-isomerasa con el suero hiperinmune del conejo que contiene anticuerpos anti-proteína disulfuro-isomerasa 1:1.000 en ( $I$ ); con el suero preinmune 1:1.000 (ii); anticuerpos anti-rotavirus 1:1000 (iii y iv). Como anticuerpo secundario se utilizó anti-conejo-HRP.

enlace hidrazona, permitió el aislamiento de la proteína disulfuro-isomerasa presente en el homogeneizado de hígado de bovino. Durante el proceso de elución, se recuperaron 30 fracciones, y la número 15 fue la de mayor absorbancia y contenido de proteína, según el análisis de SDSPAGE y Western blot (figuras 3A y 3B); sin embargo, el proceso de purificación no fue reproducible dado que, al utilizar la columna en nuevos corridos cromatográficos, cada vez hubo menor recuperación de proteína disulfuro-isomerasa, con detección de otras bandas, lo que podría indicar presencia de moléculas diferentes a dicha proteína (figura 3C).

Para analizar si en el proceso de elución con solución tampón glicina o urea $6 \mathrm{M}$ se estaba retirando anticuerpo de la columna, se realizó un Western blot de los eluidos, incubando la membrana directamente con un anticuerpo secundario anticonejo-HRP. En este caso, se observó una banda a la altura de $55 \mathrm{kDa}$, lo que sugería la presencia de la cadena pesada del anticuerpo como contaminante (figura 3C). 
A

\section{B}

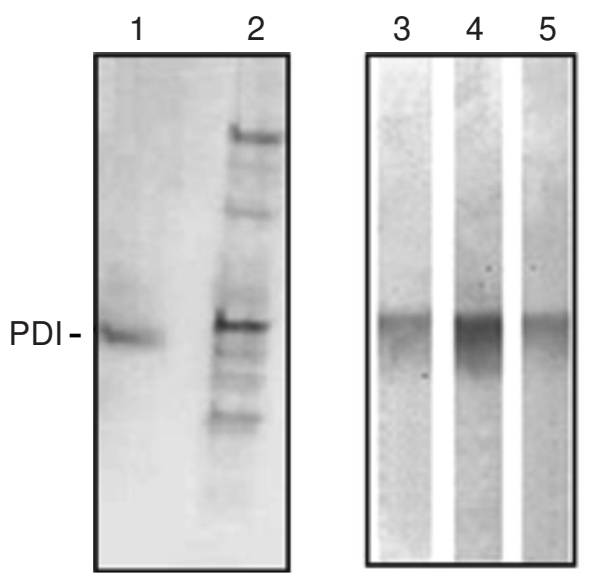

Figura 2. Detección de proteína disulfuro-isomerasa en el extracto de hígado de bovino. (A) SDS-PAGE con detección de las proteínas con azul de Coomassie. (B) Western blot en la detección de proteína disulfuro-isomerasa en el extracto de hígado de bovino con anticuerpos anti-proteína disulfuroisomerasa. Proteína disulfuro-isomerasa comercial (línea 1); extracto de hígado de bovino (líneas 2-5). Anticuerpos primarios para el Western blot, Anticuerpos anti-proteína disulfuroisomerasa comercial (línea 3); suero hiperinmune del conejo que contiene los anticuerpos anti-proteína disulfuro-isomerasa (línea 4); anticuerpos anti-proteína disulfuro-isomerasa parcialmente purificados y oxidados (línea 5).

\section{Interacción de TLP con proteína disulfuro- isomerasa in vitro}

Para determinar si existía interacción entre el rotavirus RRV y la proteína disulfuro-isomerasa in vitro, se incubaron las tres capas proteicas (500 ng de proteína viral) con proteína disulfuro-isomerasa comercial $(4$ y $8 \mu \mathrm{g}$ ). El complejo de las tres capas proteicas y proteína disulfuro-isomerasa se analizó mediante ELISA de captura. Se utilizó como anticuerpo de captura anti-rotavirus generado en cabra y la detección con los anticuerpos antiproteína disulfuro-isomerasa generados en conejo. Se detectó interacción entre el rotavirus y dicha proteína en las dos concentraciones analizadas (figura 4).

Para determinar si las partículas de los rotavirus RRV y ECwt se unían a la proteína disulfuro isomerasa purificada del extracto total de hígado, se procedió como se describió para la interacción del rotavirus RRV con la proteína comercial. La figura 5 indica que existe interacción directa entre las dos cepas de rotavirus (RRV y ECwt) con la proteína disulfuro-isomerasa purificada del hígado de bovino.
A

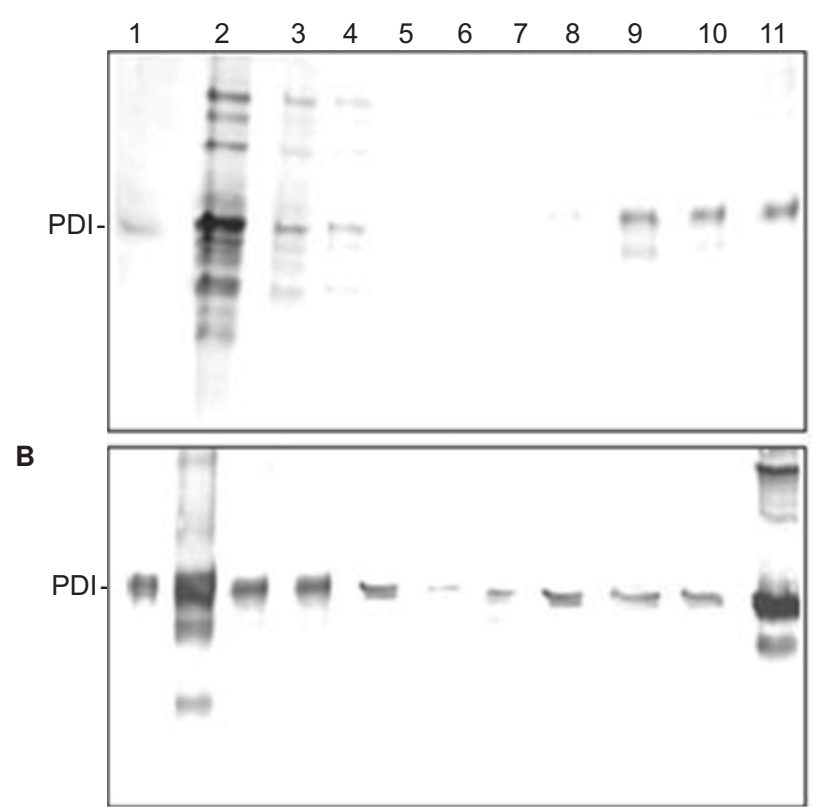

C

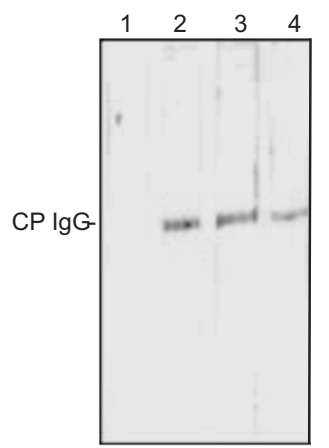

Figura 3. Aislamiento y purificación de proteína disulfuro-isomerasa. Análisis de las fracciones de la cromatografía de afinidad en el corrido I; SDS-PAGE con detección de las proteínas con azul de Coomassie (A); Western blot en la detección de proteína disulfuroisomerasa con anticuerpos anti-proteína disulfuro-isomerasa de conejo (1:1.000) de las fracciones (B). Proteína disulfuro-isomerasa comercial (línea 1); extracto de hígado de bovino (línea 2); fracciones de proteínas no retenidas (líneas 3-5); fracciones eluidas con glicina 20 mM pH 2,5: fracción No. 1 (línea 6); fracción No. 2 (línea 7); fracción No. 3 (línea 8); fracción No. 4 (línea 9); fracción No. 6 (línea 10); fracción No. 15 (línea 11). (C) Western blot en la detección de la cadena pesada de los anticuerpos (IgG) en las fracciones eluidas de diferentes corridos cromatográficos detectadas con anticuerpo anti-conejo-HRP. Fracción No. 15 corrido I (línea 1); fracciones No. 12 y 14 corrido III (líneas 2 y 3 respectivamente); fracción No.10 corrido IV (línea 4). 
Interacción del rotavirus con proteína disulfuroisomerasa de células MA104 y vellosidades intestinales

Con el propósito de determinar si el rotavirus se unía a la proteína disulfuro-isomerasa de la superficie celular, se incubaron TLP de RRV con las células MA104; de igual forma, se incubaron las tres capas proteicas de ECwt con las vellosidades aisladas de intestino de ratón lactante. La incubación se realizó a $0{ }^{\circ} \mathrm{C}$ por 45 minutos, se retiró el virus no unido por lavado $\mathrm{y}$, posteriormente, las células se incubaron durante 0,30 y 60 minutos a $37^{\circ} \mathrm{C}$. El análisis del ELISA de captura del complejo (tres capas proteicas y proteína disulfuro-isomerasa) proveniente del lisado celular de células MA104 o de las vellosidades del intestino de ratón, indica que el virus se une a proteína disulfuro-isomerasa a $4{ }^{\circ} \mathrm{C}$ y que la unión persiste durante todos los tiempos examinados a $37^{\circ} \mathrm{C}$, aunque con una ligera disminución a tiempos posteriores a 0 minutos para el sistema vellosidades-ECwt (figura 6); sin embargo, no se puede excluir la participación de otras moléculas de la célula en esta interacción.

\section{Discusión}

Los resultados recientes indican que la proteína disulfuro-isomerasa de la superficie celular está

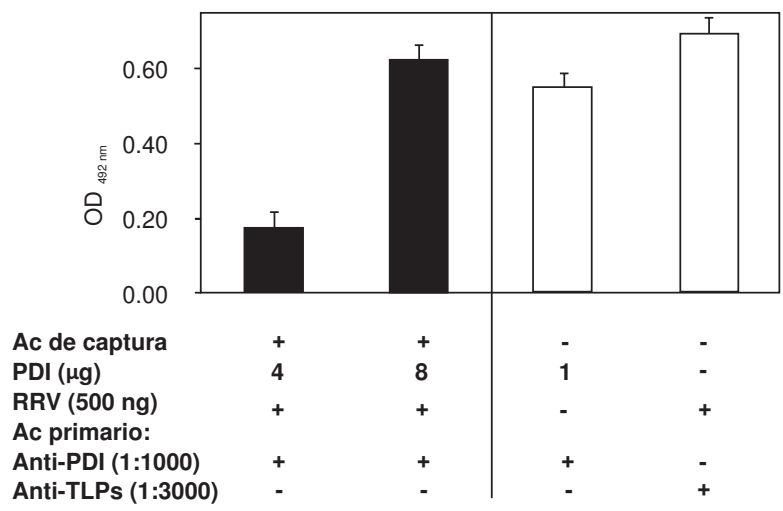

Figura 4. Interacción rotavirus RRV y proteína disulfuroisomerasa in vitro. Las tres capas proteicas de RRV se preincubaron con proteína disulfuro-isomerasa comercial. La reacción se dispensó en los pozos de ELISA, previamente sensibilizados con anticuerpos anti-rotavirus de cabra. Se utilizó Ac anti-proteína disulfuro-isomerasa de conejo como anticuerpo primario y anticuerpo anti-conejo-HRP como anticuerpo secundario. Se realizó ELISA directo como control positivo de reconocimiento de proteína disulfuro-isomerasa y rotavirus utilizando anticuerpo anti-proteína disulfuro-isomerasa y anticuerpo anti-rotavirus. El valor de absorbancia corresponde a la diferencia entre las absorbancias de los tratamientos menos aquellas que corresponden a la línea de base del experimento. Se muestran los promedios y las desviaciones estándar de uno de dos experimentos independientes realizados por duplicado.

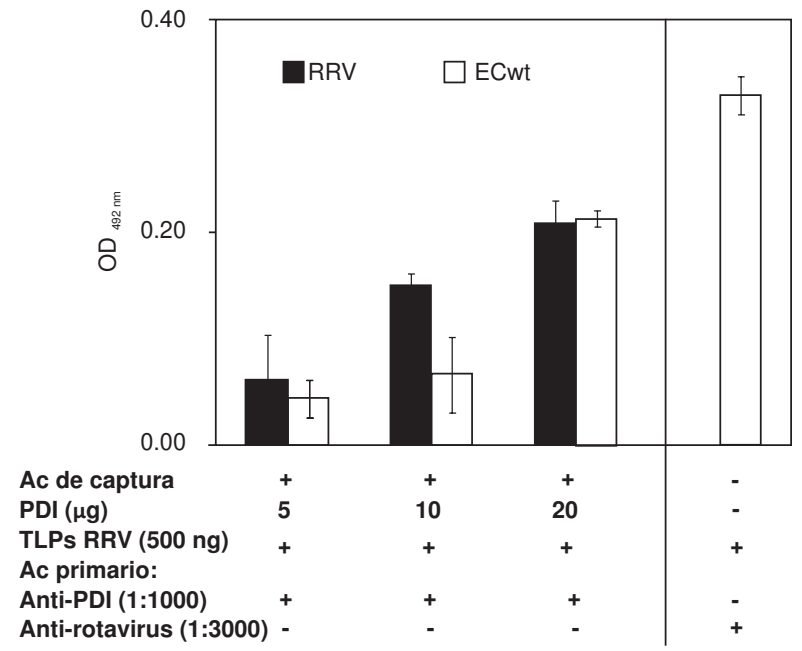

Figura 5. Interacción de rotavirus de las cepas RRV y Ecwt con proteína disulfuro-isomerasa purificada. El virus se preincubó con proteína disulfuro-isomerasa purificada del extracto de hígado de bovino. La reacción se dispensó en los pozos de ELISA, previamente sensibilizados con anticuerpos antirotavirus Ecwt de cobayo. Se utilizó como anticuerpo primario anti-proteína disulfuro-isomerasa de conejo, y como anticuerpo secundario anti-conejo-HRP. Se realizó ELISA directo como control positivo de reconocimiento del rotavirus ECwt. El valor de absorbancia corresponde a la diferencia entre las absorbancias de los tratamientos menos aquellas que corresponden a la línea de base del experimento, se muestran los promedios y las desviaciones estándar de uno de dos experimentos independientes realizados por duplicado.

implicada en el proceso de entrada de rotavirus a células MA104. El papel de la dicha proteína en la internalización del rotavirus a otras líneas celulares y al enterocito, es objeto de estudio en modelos tanto in vivo como in vitro (manuscritos en preparación). La implicación de la proteína disulfuro-isomerasa en la entrada del rotavirus a la célula huésped hace a esta proteína candidata para ser interferida en su actividad redox mediante inhibidores del intercambio tiol-disulfuro, en el contexto de la intervención terapéutica. Por lo tanto, es necesario disponer de cantidades suficientes de dicha proteína purificada para ensayos de interacción con la partícula viral y con inhibidores de la actividad redox. La purificación cromatográfica de esta proteína en el presente trabajo contribuye a este propósito.

El suero policlonal hiperinmune generado contra proteína disulfuro-isomerasa en conejo preservó la capacidad de reconocimiento de su correspondiente antígeno, después de haber sido purificado parcialmente y sometido a oxidación para su utilización cromatográfica. Se encontró, de acuerdo con los resultados del Western blot, que este antisuero policlonal reconocía principalmente 


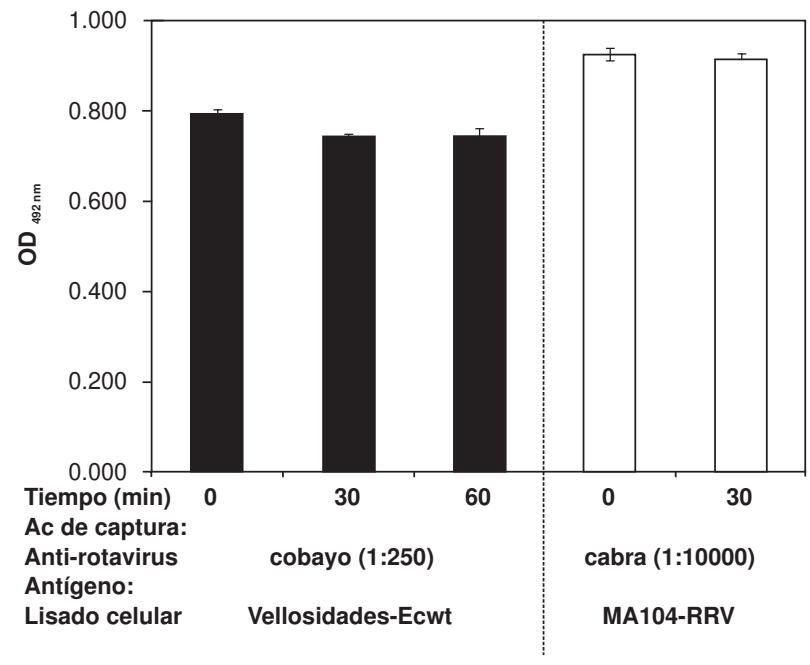

Figura 6. Interacción de rotavirus de las cepas Ecwt y RRV con proteína disulfuro-isomerasa de vellosidades intestinales o células MA104. Las tres capas proteicas de Ecwt o RRV se incubaron con las vellosidades intestinales de ratón o las células MA104, respectivamente. Los lisados celulares se dispensaron en cada pozo de ELISA, previamente sensibilizado con anticuerpos anti-rotavirus de cobayo (ECwt) o cabra (para RRV). Se utilizó como anticuerpo primario anti-proteína disulfuro-isomerasa de conejo y como anticuerpo secundario anti-conejo-HRP. El valor de absorbancia corresponde a la diferencia entre las absorbancias de los tratamientos menos aquellas que corresponden a la línea de base del experimento. Se muestran los promedios y las desviaciones estándar de uno de dos experimentos independientes realizados por duplicado.

la banda de proteína correspondiente a proteína disulfuro-isomerasa, cuando fue utilizado hasta en una dilución de 1:3.000. El patrón de bandas reactivas al suero hiperinmune fue similar al encontrado utilizando anticuerpos policlonales de origen comercial. La especificidad del reconocimiento de los anticuerpos policlonales generados en conejo hizo posible la purificación de proteína disulfuroisomerasa sin proteínas contaminantes, teniendo en cuenta que proteínas unidas inespecíficamente a la columna pueden ser eficientemente eliminadas en la fase de lavado. Este suero hiperinmune también fue capaz de reconocer la proteína disulfuro-isomerasa en su conformación nativa en ELISA. Las anteriores propiedades de este suero policlonal permitieron la evaluación consistente y reproducible de la interacción directa de las tres capas proteicas y la proteína disulfuro-isomerasa mediante un ensayo inmunoenzimático in vitro de este complejo.

La cromatografía de afinidad permitió la purificación parcial de proteína disulfuro-isomerasa. Sin embargo, al examinar la calidad de proteínas eluidas en posteriores corridas cromatográficas, se evidenció la presencia de la cadena pesada de las inmunoglobulinas como contaminación. Una de las desventajas de las cromatografías de afinidad es que no siempre el ligando es liberado completamente, en especial cuando las afinidades entre el ligando y el anticuerpo son muy fuertes. Cuando esto ocurre, se utilizan condiciones más drásticas que, generalmente, llegan hasta desnaturalizar el anticuerpo y el antígeno, e incluso, como lo sucedido en el presente trabajo, el desprendimiento del anticuerpo. Otras condiciones de elución con ácidos o agentes caotrópicos no fueron de primera elección debido a que se quiso preservar el carácter funcional de la proteína disulfuro-isomerasa.

La evaluación de la interacción entre las tres capas proteicas y la proteína disulfuro-isomerasa fue un aspecto central del trabajo aquí descrito. Cuando se incubaron las tres capas proteicas de rotavirus $R R V$ con la proteína disulfuro-isomerasa comercial en un ensayo in vitro, se encontró que dicha proteína se une a las tres capas proteicas de manera dependiente de la concentración, lo que sugiere que se trata de una interacción específica entre la proteína y la partícula de rotavirus. El mismo resultado se obtuvo al mezclar la proteína disulfuro-isomerasa obtenida de la extracción de hígado de bovino, con las partículas de los rotavirus RRV y ECwt.

La posible interacción de las partículas rotavirales con la proteína disulfuro-isomerasa celular fue evaluada en dos sistemas celulares. Se encontraron resultados positivos de unión de la cepa RRV a las células MA104 y de la cepa ECwt en contacto con las células de las vellosidades intestinales aisladas de ratón, por medio de la interacción con proteína disulfuro-isomerasa celular. Sin embargo, la magnitud de la interacción de la cepa RRV con dicha proteína no pareció variar significativamente durante los primeros 30 minutos de incubación a $37^{\circ} \mathrm{C}$; mientras que la interacción ECwt-proteína disulfuro-isomerasa pareció decrecer levemente a 30 y 60 minutos después de la incubación. Al aplicar las tres capas proteicas al cultivo de vellosidades o de células MA104, estas partículas sólo se pueden unir a la célula por medio de sus proteínas estructurales de la capa más externa durante los eventos tempranos de unión. De esta manera, la proteína disulfuro-isomerasa detectada en la prueba de ELISA, independientemente de que ella provenga del medio intracelular o de la superficie celular, corresponde a aquella unida a las proteínas estructurales de las tres capas proteicas capturadas en este ensayo inmunoenzimático. 
Sin embargo, no se descarta que, a diferencia de la interacción in vitro, en el sistema celular la unión de la proteína disulfuro isomerasa con la partícula viral pueda incluir interacciones indirectas mediadas por otras proteínas presentes en el lisado celular. Es interesante destacar que tanto las células MA104 (línea celular de epitelio de riñón de mono rhesus) como las células de vellosidades intestinales de ratón, parecen compartir una interacción con las partículas de rotavirus, la cual involucra a la proteína disulfuro-isomerasa.

En varios tipos de células se ha encontrado que la proteína disulfuro-isomerasa de la superficie celular es reductora, mientras que la proteína intracelular es oxidante $(26,31,32)$. Con base en los resultados previos obtenidos en nuestro laboratorio (Calderón MN, Acosta O, Guerrero CA, Guzmán F. Protein disulfide isomerase activity is involved in rotavirus entry to MA104 cells. Proceedings of the XIV International Congress of Virology, Istanbul. 2008; p. 163-4), la actividad de la proteína disulfuroisomerasa está implicada en los eventos tempranos de entrada del rotavirus a la célula.

Este hallazgo nos permite sugerir que las proteínas estructurales del rotavirus, tales como VP4 (VP5* 0 VP8*), VP6 y VP7 (52-54), son sustratos potenciales de la actividad reduct2ora de la proteína disulfuroisomerasa, especialmente, en el evento de estar oxidadas en sus cisteínas. Aunque VP5* y VP8* fueron reportadas como proteínas que contenían enlaces disulfuro (52), estudios cristalográficos recientes indican que sus cisteínas exhiben grupos tiol (55-58), así mismo como VP6 (53).

Por otra parte, se ha encontrado por cristalografía que VP7 contiene cuatro enlaces de disulfuro (53). Los resultados aquí presentados permitieron evidenciar que existe interacción directa entre el rotavirus y la proteína disulfuro-isomerasa en un sistema in vitro; sin embargo, se deben explorar otras metodologías (como la espectrometría de masas) (54) para caracterizar esta interacción e incorporarla al contexto de los eventos tempranos que tienen lugar durante la entrada del rotavirus a la célula huésped natural.

\section{Conflicto de intereses}

No existe conflicto de intereses.

Financiación

Este trabajo fue financiado por Colciencias (código 1101-405-20300, contrato 193-2007).

\section{Referencias}

1. Parashar U, Bresee J, Glass R. Rotavirus and severe childhood diarrhea. Emerg Infect Dis. 2006;12:304-6.

2. Danchin $\mathbf{M H}$, Bines JE. Defeating rotavirus? The Global Recommendation for Rotavirus Vaccination. N Engl J Med. 2009;361:19-21.

3. Khamrin P, Maneekarn N, Peerakome S, Chan-it W, Yagyu F, Okitsu S, et al. Novel porcine rotavirus of genotype P[27] shares new phylogenetic lineage with G2 porcine rotavirus strain. Virology. 2007;361:243-52.

4. Polanco G, González M, Manzano L, Cámara J, Puerto M. Rotavirus en animales asintomáticos: detección y clasificación antigénica. Arch Med Vet. 2004;36:65-70.

5. Pesavento JB, Crawford SE, Estes MK, Prasad BV. Rotavirus proteins: Structure and assembly. Curr Top Microbiol Immunol. 2006;309:189-219.

6. Jayaram H, Estes MK, Prasad VB. Emerging themes in rotavirus cell entry, genome organization, transcription and replication. Virus Res. 2004;101:67-81.

7. Estes M. Rotaviruses and their replication. In: Knipe DM, Howley PM, editors. Fields virology. 4th ed. Philadelphia: Lippincott- Raven Publishers; 2001. p. 1747-85.

8. Coulson BS, Londrigan SL, Lee DJ. Rotavirus contains integrin ligand sequences and a disintegrin-like domain that are implicated in virus entry into cells. Proc Natl Acad Sci USA. 1997;94:5389-94

9. Guerrero CA, Méndez E, Zarate S, Isa P, López S, Arias CF. Integrin av $\beta 3$ mediates rotavirus cell entry. Proc Nat Acad Sci USA. 2000;97:14644-9.

10. Zárate S, Espinosa R, Romero P, Guerrero CA, Arias CF, López S. Integrin a2 $\beta 1$ mediates the cell attachment of the rotavirus neuraminidase-resistant variant nar3. Virology. 2000;278:50-4.

11. Hewish M, Takada Y, Coulson BS. Integrins a2 $\beta 1$ and a4 $\beta 1$ can mediate SA11 rotavirus attachment and entry into cells. J Virol. 2000;74:228-36.

12. Ciarlet M, Crawford SE, Cheng E, Blutt SE, Daren A, Rice DA, et al. VLA-2 (a2 $\beta 1$ ) integrin promotes rotavirus entry into cells but is not necessary for rotavirus attachment. J Virol. 2002;76:1109-23.

13. Londrigan SL, Graham KL, Takada Y, Halasz P, Coulson BS. Monkey rotavirus binding to a2 $\beta 1$ integrin requires the a2 I domain and is facilitated by the homologous $\beta 1$ subunit. J Virol. 2003;77:9486-501.

14. Graham KL, Halasz P, Tan Y, Hewish MJ, Takada Y, Mackow ER, et al. Integrin-using rotaviruses bind a2 $\beta 1$ integrin a2 I domain via VP4 DGE sequence and recognize aX $\beta 2$ and $\mathrm{aV} \beta 3$ by using VP7 during cell entry. J Virol. 2003;77:9969-78.

15. Graham KL, Fleming FE, Halasz P, Hewish MJ, Nagesha $\mathbf{H}$, Holmes IH, et al. Rotaviruses interact with a4 $\beta 7$ and a4 $\beta 1$ integrins by binding the same integrin domains as natural ligands. J Gen Virol. 2005;86:3397-408.

16. Graham KL, Takada Y, Coulson BS. Rotavirus spike protein VP5* binds a2 $\beta 1$ integrin on the cell surface and competes with virus for cell binding and infectivity. J Gen Virol. 2006;87:1275-83. 
17. Guerrero CA, Bouyssounade D, Zárate S, Isa P, López $\mathbf{T}$, Espinosa R, et al. Heat shock cognate protein 70 is involved in rotavirus cell entry. J Virol. 2002;76:4096-102.

18. Guerrero CA, Zárate S, Corkidi SG, López S, Arias CF. Biochemical characterization of rotavirus receptors in MA104 cells. J Virol. 2000;74:9362-71.

19. Zárate S, Cuadras MA, Espinosa R, Romero P, Juárez $\mathrm{KO}$, Camacho-Nuez M, et al. Interaction of rotaviruses with Hsc70 during cell entry is mediated by VP5. J Virol. 2003;77:7254-60.

20. Pérez-Vargas J, Romero P, López S, Arias CF. Peptidebinding and ATPase domains of recombinant hsc70 are required to interact with rotavirus and reduce its infectivity. $J$ Virol. 2006;80:3322-31.

21. Gualtero DF, Guzmán F, Acosta 0 , Guerrero CA. Amino acid domains 280-297 of VP6 and 531-554 of VP4 are implicated in heat shock cognate protein hsc70-mediated rotavirus infection. Arch Virol. 2007;152:2183-96.

22. López S, Arias CF. Multistep entry of rotavirus into cells: A Versaillesque dance. Trends Microbiol. 2004;12:271-8.

23. López S, Arias CF. Early steps in rotavirus cell entry. Curr Top Microbiol Immunol. 2006;309:39-66.

24. Trask SD, Dormitzer PR. Assembly of highly infectious rotavirus particles recoated with recombinant outer capsid proteins. J Virol. 2006;80:11293-304.

25. Mamathambika BS, Bardwell JC. Disulfide-linked protein folding pathways. Annu Rev Cell Dev Biol. 2008;24:211-35.

26. Turano C, Coppari S, Altieri F, Ferraro A. Proteins of the PDI family: Unpredicted non-ER locations and functions. J Cell Physiol. 2002;193:154-63.

27. Appenzeller-Herzog C, Ellgaard L. The human PDI family: Versatile packed into a single fold. Biochim Biophys Acta. 2008;1783:535-48.

28. Ellgaard L, Ruddock LW. The human protein disulphide isomerase family: Substrate interactions and functional properties. EMBO Rep. 2005;6:28-32.

29. Ferrari D, Soling HD. The protein disulphide-isomerase family: Unravelling a string of folds. Biochem J. 1999; 339:1-10.

30. Hawkins HC, Blackburn EC, Freedman RB. Comparison of the activities of protein disulphide-isomerase and thioredoxin in catalyzing disulphide isomerization in a protein substrate. Biochem J. 1991;275:349-53.

31. Jordan PA, Gibbins JM. Extracellular disulfide exchange and the regulation of cell function. Antioxid Redox Signal. 2006;8:312-24

32. Gallina A, Mandel R, Trahey M, Broder CC, Ryser HJ. Inhibitors of protein disulfide isomerase prevent cleavage of disulfide bonds in receptor bound glycoprotein 120 and prevent HIV-1 entry. J Biol Chem. 2002;277:50579-88.

33. Tager M, Kroning H, Thiel U, Ansorge S. Membrane-bound protein disulfide isomerase PDI is involved in regulation of surface expression of thiols and drug sensitivity of B-CLL cells. Exp Hematol.1997;25:601-7.

34. Essex DW. Redox control of platelet function. Antioxid Redox Signal. 2009;11:1191-225.
35. Lahav J. A new regulatory disulfide isomerase on the platelet surface. Blood. 2005;105:1378-9.

36. Jordan PA, Stevens JM, Hubbard GP, Barrett NE, Sage T, Authi KS, et al. A role for the thiol isomerase protein ERP5 in platelet function. Blood. 2005;105:1500-7.

37. Mandel R, Ryser HJ, Ghani F, Wu M, Peak D. Inhibition of a reductive function of the plasma membrane by bacitracin and antibodies against protein disulfide-isomerase. Proc Natl Acad Sci USA. 1993;90:4112-6.

38. O'Neill S, Robinson A, Deering A, Ryan M, Fitzgerald DJ, Moran N. The platelet integrin allb $\beta 3$ has an endogenous thiol isomerase activity. J Biol Chem. 2000;275:36984-90.

39. Swiatkowska M, Szymanski J, Padula G Cierniewski CS. Interaction and functional association of protein disulfide isomerase with $a_{\mathrm{v}} \beta_{3}$ integrin on endothelial cells. FEBS J. 2008;275:1813-23.

40. Abell BA, Brown DT. Sindbis virus membrane fusion is mediated by reduction of glycoprotein disulfide bridges at the cell surface. J Virol. 1993;67:5496-501.

41. Ryser HJ, Levy EM, Mandel R, DiSciullo GJ. Inhibition of human immunodeficiency virus infection by agents that interfere with thiol-disulfide interchange upon virus-receptor interaction. Proc Nat Acad Sci USA. 1994;91:4559-63.

42. Markovic I, Stantchev TS, Fields KH, Tiffany LJ, Tomiç $M$, Weiss $C D$, et al. Thiol/disulfide exchange is a prerequisite for CXCR4-tropic HIV-1 envelope-mediated T-cell fusion during viral entry. Blood. 2004;103:1586-94.

43. Ryser HJ, Flückiger R. Progress in targeting HIV-1 entry. Drug Discov Today. 2005;10:1085-94.

44. Auwerx J, Isacsson $\mathrm{O}$, Söderlund J, Balzarini J, Johansson $\mathbf{M}$, Lundberg $\mathbf{M}$. Human glutaredoxin-1 catalyzes the reduction of HIV-1 gp120 and CD4 disulfides and its inhibition reduces HIV-1 replication. Int $\mathrm{J}$ Biochem Cell Biol. 2009;41:1269-75.

45. Ou W, Silver J. Role of protein disulfide isomerase and other thiol-reactive proteins in HIV-1 envelope proteinmediated fusion. Virology. 2006;350:406-17.

46. Jain S, McGinnes LW, Morrison TG. Thiol/disulfide exchange is required for membrane fusion directed. J Virol. 2007;81:2328-39.

47. Jain S, McGinnes LW, Morrison TG. Overexpression of thiol/disulfide isomerases enhances membrane fusion directed by the Newcastle disease virus fusion protein. $J$ Virol. 2008;82:12039-48.

48. Jain S, McGinnes LW, Morrison TG. Role of thiol/ disulfide exchange in Newcastle disease virus entry. J Virol. 2009;83:241-9.

49. Abou-Jaoude G, Sureau C. Entry of hepatitis delta virus requires the conserved cysteine residues of the hepatitis $B$ virus envelope protein antigenic loop and is blocked by inhibitors of thiol-disulfide exchange. J Virol. 2007;81:1305766.

50. Guerrero CA, Santana AY, Acosta O. Mouse intestinal villi as a model system for studies of rotavirus infection. J Virol Methods. 2010;168:22-30

51. Lizano M, López S, Arias CF. The amino-terminal half of rotavirus SA114fM VP4 protein contains a hemagglutination 
domain and primes for neutralizing antibodies to the virus. $J$ Virol. 1991;65:1383-91.

52. Patton JT, Hua J, Mansell EA. Location of intrachain disulfide bonds in the VP5* and VP8* trypsin cleavage fragments of the rhesus rotavirus spike protein VP4. J Virol. 1993;67:4848-55.

53. Mathieu M, Petitpas I, Navaza J, Lepault J, Kohli E, Pothier P, et al. Atomic structure of the major capsid protein of rotavirus: Implications for the architecture of the virion. EMBO J. 1993;20:1485-97.

54. Aoki ST, Settembre EC, Trask SD, Greenberg HB, Harrison SC, Dormitzer PR. Structure of rotavirus outerlayer protein VP7 bound with a neutralizing Fab. Science. 2009;324:1444-7.
55. Dormitzer PR, Nason EB, Prasad BV, Harrison SC. Structural rearrangements in the membrane penetration protein of a non-enveloped virus. Nature. 2004;430:1053-8.

56. Yoder JD, Trask SD, Vo TP, Binka M, Feng N, Harrison SC, et al. VP5* rearranges when rotavirus uncoats. J Virol. 2009;83:11372-7.

57. Dormitzer PR, Sun ZY, Wagner G, Harrison SC. The rhesus rotavirus VP4 sialic acid binding domain has a galectin fold with a novel carbohydrate binding site. EMBO J. 2002;21:885-97.

58. Trauger S, Junker T, Siuzdak G. Investigating viral proteins and intact viruses with mass spectrometry. Top Curr Chem. 2003;225:265-82. 